\title{
Improvement of the therapeutic capacity of insulin-producing cells trans-differentiated from human liver cells using engineered cell sheet
}

Yu Na Lee ${ }^{1+}$, Hye-Jin $\mathrm{Yi}^{1+}$, Eun Hye Seo ${ }^{1}$, Jooyun Oh${ }^{1}$, Song Lee ${ }^{1}$, Sarah Ferber ${ }^{2}$, Teruo Okano ${ }^{3,4}$, In Kyong Shim ${ }^{1 *}$ id and Song Cheol Kim ${ }^{1,5^{*}}$

\begin{abstract}
Background: Although pancreatic islet transplantation therapy is ideal for diabetes patients, several hurdles have prevented it from becoming a standard treatment, including donor shortage and low engraftment efficacy. In this study, we prepared insulin-producing cells trans-differentiated from adult human liver cells as a new islet source. Also, cell sheet formation could improve differentiation efficiency and graft survival.

Methods: Liver cells were expanded in vitro and trans-differentiated to IPCs using adenovirus vectors carrying human genes for PDX1, NEUROD1, and MAFA. IPCs were seeded on temperature-responsive culture dishes to form cell sheets. Differentiation efficiency was confirmed by $B$ cell-specific gene expression, insulin production, and immunohistochemistry. IPC suspension was injected by portal vein (PV), and IPC sheet was transplanted on the liver surface of the diabetic nude mouse. The therapeutic effect of IPC sheet was evaluated by comparing blood glucose control, weight gain, histological evaluation, and hepatotoxicity with IPC injection group. Also, cell biodistribution was assessed by in vivo/ex vivo fluorescence image tagging.

Results: Insulin gene expression and protein production were significantly increased on IPC sheets compared with those in IPCs cultured on conventional culture dishes. Transplanted IPC sheets displayed significantly higher engraftment efficiency and fewer transplanted cells in other organs than injected IPCs, and also lower liver toxicity, improved blood glucose levels, and weight gain. Immunohistochemical analyses of liver tissue revealed positive staining for PDX1 and insulin at 1, 2, and 4 weeks after IPC transplantation.

Conclusions: In conclusion, cell sheet formation enhanced the differentiation function and maturation of IPCs in vitro. Additionally, parameters for clinical application such as distribution, therapeutic efficacy, and toxicity were favorable. The cell sheet technique may be used with IPCs derived from various cell sources in clinical applications.
\end{abstract}

Keywords: Liver cell, Insulin-producing cell, Diabetics, Cell sheet, Transplantation

\footnotetext{
*Correspondence: shimiink@gmail.com; drksc@amc.seoul.kr

${ }^{\dagger} \mathrm{Yu} \mathrm{Na}$ Lee and Hye-Jin Yi contributed equally to this work.

${ }^{1}$ Asan Institute for Life Sciences, Asan Medical Center, University of Ulsan College of Medicine, Seoul, Republic of Korea

Full list of author information is available at the end of the article
}

(C) The Author(s). 2021 Open Access This article is licensed under a Creative Commons Attribution 4.0 International License, which permits use, sharing, adaptation, distribution and reproduction in any medium or format, as long as you give appropriate credit to the original author(s) and the source, provide a link to the Creative Commons licence, and indicate if changes were made. The images or other third party material in this article are included in the article's Creative Commons licence, unless indicated otherwise in a credit line to the material. If material is not included in the article's Creative Commons licence and your intended use is not permitted by statutory regulation or exceeds the permitted use, you will need to obtain permission directly from the copyright holder. To view a copy of this licence, visit http://creativecommons.org/licenses/by/4.0/ The Creative Commons Public Domain Dedication waiver (http://creativecommons.org/publicdomain/zero/1.0/) applies to the data made available in this article, unless otherwise stated in a credit line to the data. 


\section{Background}

Diabetes causes multiple systemic complications such as blindness, kidney failure, heart attacks, stroke, and diabetic neuropathy, which reduce life expectancy and impose enormous health costs worldwide [1]. Insulin therapy is the most effective method for reducing hyperglycemia. However, general insulin therapy cannot prevent severe hypoglycemia and long-term complications [2-4]. Strict glycemic control has been emphasized in the management of diabetes $[5,6]$. Currently, pancreas and islet-cell transplantations are the only treatment modalities to prevent late complications of insulindependent diabetes. Islet transplantation is comparatively simple and non-invasive, in contrast to pancreas transplantation. Shapiro et al. examined seven patients successfully treated for insulin dependence for 1 year after islet implantation. Over the long follow-up, transplanted islets showed progressive loss of function, and many patients required insulin therapy [7]. Many limitations must be overcome for successful islet transplantation. Developing autologous insulin-producing cells (IPCs) from patients is an ideal solution to overcome the current islet transplantation limitations, including the shortage of donors and immune reactions of the allograft [8].

Use of liver cells from the liver has attracted considerable attention. These cells are considered a good source for trans-differentiation into pancreatic cells because they share a common developmental origin with the pancreas and are free from the safety risks associated with stem cells $[9,10]$. Recent studies demonstrated that adult cells or stem cells can be induced to the pancreatic lineage by overexpressing pancreatic and duodenal homeobox 1 (PDX1), which is crucial for pancreatic organogenesis and beta cell function [11, 12]. Additionally, various transcription factors play important roles in the differentiation and maturation of IPCs, including neurogenin-3 (NGN3), neuronal differentiation 1 (NEUROD1), and MAFA [13]. Interestingly, BernemanZeitouni et al. showed that the temporal and hierarchical combination of three pancreatic transcription factors, PDX1, paired box 4 (PAX4), and v-maf musculoaponeurotic fibrosarcoma oncogene family, protein A (MAFA), enhanced mature $\beta$ cell-like characteristics [14]. The development of a variety of factors has resulted in improvements in differentiation capability that includes insulin gene expression and in vivo insulin secretion in vitro.

Cell sheets are harvested from temperature-responsive culture dishes by inducing temperature change, which enables them to maintain cell-cell connections and adhesive proteins on their basal side. This facilitates attachment to target sites in other tissues. Cell sheets have the potential to deliver a large number of cells to the desired organ without the loss of transplanted cells [15]. Clinically, pancreatic islet transplantation is conducted via the intraportal route [16]. When islets are administered directly through the portal vein, many cells engraft in the liver through smaller venules, enabling the liver to supply blood with near-physiological insulin delivery [17]. However, concerns with intraportal islet infusion include procedure-related complications, bleeding, hepatic hypertension, and thrombosis [16]. Particularly, the cell transplantation efficiency is quite low and the instant blood-mediated inflammatory reaction causes rapid islet loss [18, 19].

The purpose of the present study was to investigate the effect of IPC sheets trans-differentiated from human liver cells in enhancing the differentiation efficiency and graft survival of IPCs. We compared pancreatic lineagerelated gene expression and insulin secretion on IPC sheets to those in IPCs cultured on conventional culture dishes. To assess the therapeutic efficacy, biodistribution, and safety of IPC sheets, we compared two different techniques for transplantation into the liver: a single injection of IPCs through the portal vein and transplantation of the IPC sheet onto the liver surface.

\section{Methods}

Isolation of human liver cells

Adult liver cells were isolated and cultured as previously described [11, 14]. This study was carried out according to the guidelines and with the approval of the Institutional Review Board of Asan Medical Center (IRB number: 2014-1182 Seoul, Republic of Korea). Liver tissue was obtained from donors undergoing abdominal surgery; informed consent was obtained from the patients for this procedure. In the case of non-diabetic patients and patients with type 2 diabetes, liver tissues were obtained with consent from patients who underwent pancreatic surgery due to benign pancreatic disease. In the case of patients with type 1 diabetes, liver tissue was obtained with consent from patients who underwent abdominal surgery for pancreatic transplantation. The selection criteria for liver tissue biopsy participants included patients undergoing pancreatic resection due to pancreatitis, pancreatic transplantation, or hepatectomy. Pancreatic tumors and pancreatic cancer were excluded from analyses. Exclusion criteria included patients with cholangiohepatitis prior to surgery, bilirubin $>2 \mathrm{mg} / \mathrm{dL}$ or more, class $\mathrm{B}, \mathrm{C}$ on liver function tests, and patients with uncorrected coagulation disorder. Patients whose liver function was expected to be abnormal were excluded. In addition, the liver tissues were confirmed to be normal liver tissues through histology analysis. Donors had an average age of $50.2 \pm 16.1 ; 14$ men and 24 women acted as donors. Liver tissues were digested by $0.16 \%$ collagenase type I (Worthington Biochemical, NJ, USA) and plated on fibronectin-coated plates $\left(3 \mu \mathrm{g} / \mathrm{cm}^{2}\right.$, Sigma-Aldrich, St. Louis, MO, USA). The cells were 
cultured in Dulbecco's modified Eagle's medium supplemented with $10 \%$ fetal bovine serum (FBS), 1\% antibiotic-antimycotic, and Glutamax (Life Technologies, Carlsbad, CA, USA). The medium was changed daily during the first 3 days to remove non-adherent cells, and from the fourth day onwards, the medium was changed every 2 or 3 days. Liver cells were passaged when approaching confluence using trypsin-EDTA. After propagation, liver cells from passages 5 to 7 were used for the experiments. To evaluate the growth characteristics of the isolated liver cells, the time required by the cells to proliferate (doubling time) was measured. At every passage, we seeded $2.5 \times 10^{5}$ cells in $100-\mathrm{mm}$ culture dishes. At confluence, the cells were harvested and counted using trypan blue staining. Population doubling time was determined using a previously reported formula [20] and was confirmed using an online doubling time calculator application.

\section{Characterization of liver cells}

We confirmed surface marker expression and differentiation capacity of liver cells. Liver cells at early (1-2), mid (6-7), and late (12-14) passages were blocked with $1 \%$ bovine serum albumin and incubated for $1 \mathrm{~h}$ at $4{ }^{\circ} \mathrm{C}$ with the following anti-human antibodies conjugated with phycoerythrin (PE): mouse IgG1 isotype control, CD31, CD45, CD90, CD73, and CD105 (BD Biosciences, San Jose, CA, USA). Additionally, HLA-DR was analyzed to determine the immune properties. Cells were analyzed using a FACSCalibur device (BD Biosciences). For analyzing albumin expression and ectopic gene expression of PDX1, NEUROD1, and MAFA, liver cells were fixed and permeabilized using eBioscience ${ }^{\text {Th }}$ Foxp3/Transcription factor staining buffer set (Thermo Fisher Scientific, Waltham, MA, USA) and were stained using indirect method. Furthermore, the cells were stained using rabbit anti-PDX1, mouse anti-NEUROD1, and rabbit anti-MAFA (1:200; Abcam). For secondary fluorescence labeling, the cells were incubated with antirabbit IgG Alexa Fluor 488 and anti-mouse Alexa 555 (1200; Thermo Fisher Scientific). To confirm the introduction of PDX1, NeuroD1, and MAFA genes in cells using flow cytometry, the liver cells in which the transcription factor genes (PDX1, NEUROD1, and MAFA) were not introduced were stained in the same way as gene transduced cells. For albumin control, primary mouse IgG1 isotype control was used as primary antibody instead of mouse anti-albumin.

For adipogenic and osteogenic differentiation, we used the adipogenic or osteogenic differentiation media (Lonza, Basel, Switzerland). After 14 days in culture, the adipogenic culture formed vacuoles. The plates were fixed and stained with Oil Red O (Sigma-Aldrich). The osteogenic differentiation cultures were incubated for 28 days and fixed and stained with 1\% Alizarin Red solution pH 4.1 (Sigma-Aldrich). We also confirmed the expression of albumin by isolated liver cells at early $(1-2)$, mid (6-7), and late (12-14) passages. Albumin expression were analyzed by flow cytometry and immunofluorescence staining. For immunofluorescence staining, cells were fixed with $4 \%$ paraformaldehyde (Merck, Darmstadt, Germany) and permeabilized with $0.1 \%$ Triton X100. After antibody blocking, primary antibodies were incubated overnight at $4{ }^{\circ} \mathrm{C}$. We used mouse antialbumin (1:100, Santa Cruz Biotechnology, Dallas, TX, USA) and anti-mouse Alexa 488 (1:200; Thermo Fisher Scientific, Waltham, MA, USA). ProLong Gold antifade reagent with 4',6-diamidino-2-phenylindole (DAPI, Thermo Fisher Scientific) was used to stain the nuclei and for mounting. The slides were examined using the EVOS $^{\circ} \mathrm{FL}$ auto cell imaging system (Thermo Fisher Scientific).

\section{Preparation of IPCs and IPC sheets}

To induce trans-differentiation, $ß$ cell-related transcription factors were transduced into liver cells. PDX1, NEUROD1, and MAFA were selected and transduced with adenovirus expressing vectors. Ad-CMV-hPDX1, AdCMV-hNEUROD1, Ad-CMV-MAFA, and Ad-CMV-GFP were obtained from Vector Biolabs (Burlingame, CA, USA). Ad-RIP-luciferase was generously provided by Orgenesis, Inc. (Germantown, MD, USA). The expression of green fluorescent protein (GFP) after transduction of GFP for 2 days was assessed by flow cytometry. Liver cells were transduced with PDX1 and NEUROD1 for 2 days, followed by replacement of the medium with medium containing MAFA for 3 days. Liver cells were cultured in $10 \mathrm{mM}$ nicotinamide (Sigma-Aldrich), $20 \mathrm{ng} / \mathrm{mL}$ epidermal growth factor (PeproTech, Rocky Hill, NJ, USA), and $5 \mathrm{nM}$ exendin-4 (Sigma-Aldrich) included in the culture medium. The optimal MOI was determined according to GFP transduction efficiency, cell survival, insulin promotor activity, and insulin gene expression under various conditions. MOIs of the viruses were 500, 250, 50, 200, and 200 for PDX1, NEUROD1, MAFA, GFP, and luciferase, respectively.

The scheme of this study is summarized in Fig. 1a. IPCs and the IPC sheets grown on culture dishes were transduced simultaneously with PDX1 and NEUROD1 for 2 days. Next, cells were harvested and re-seeded in commercially available PIPAAm dishes (UpCell; CellSeed, Inc., Tokyo, Japan)-having temperature-responsive properties-to prepare the IPC sheets. For the differentiation of IPCs, cells were re-seeded in culture dishes at a concentration of $10^{6} / 100 \mathrm{~mm}$. MAFA was transduced into IPCs and IPC sheets when cells were re-seeded. On the next day (day 3 after initial virus exposure), the differentiation media were replenished in IPC-seeded culture plates. In 


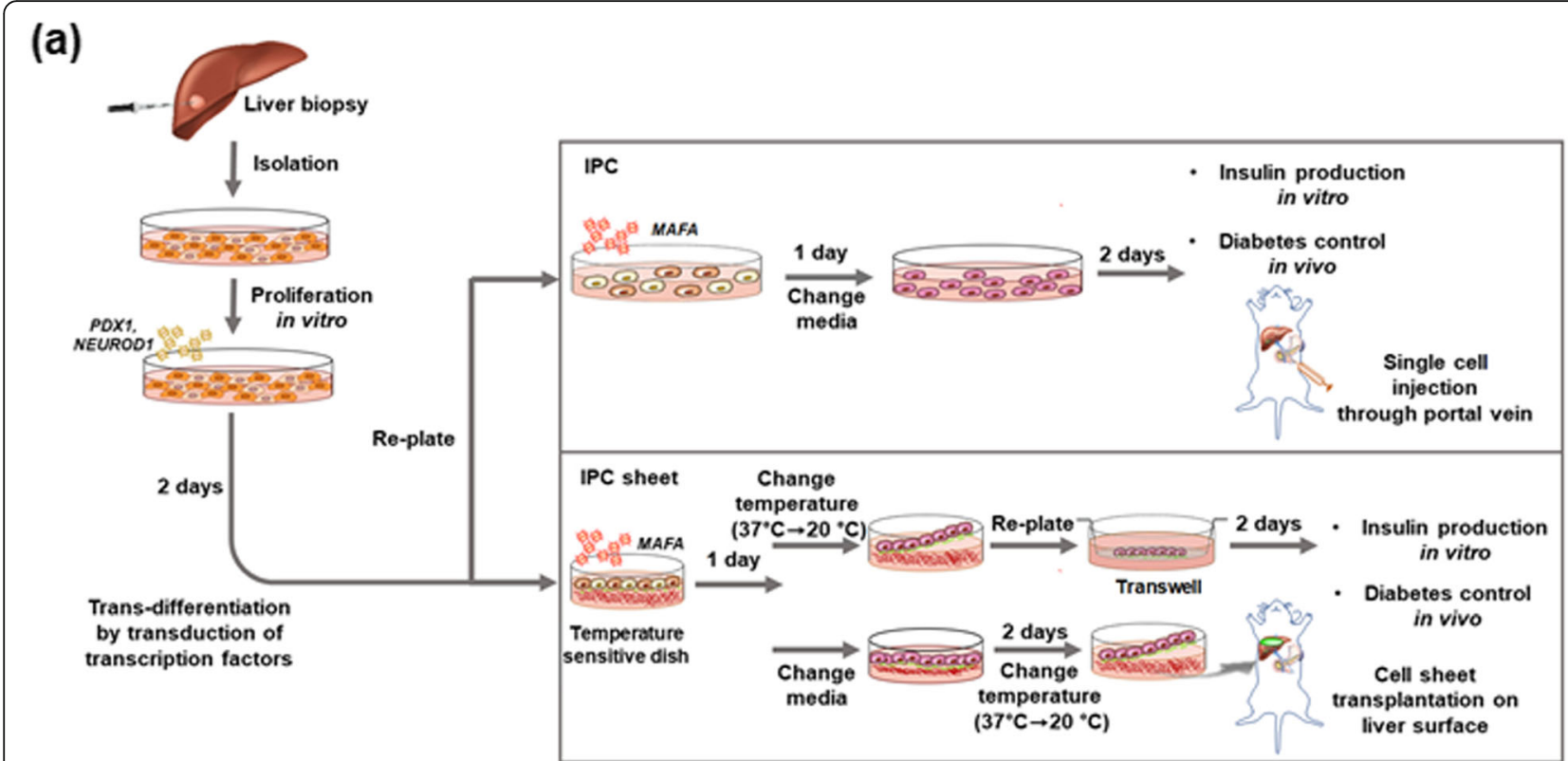

(b)
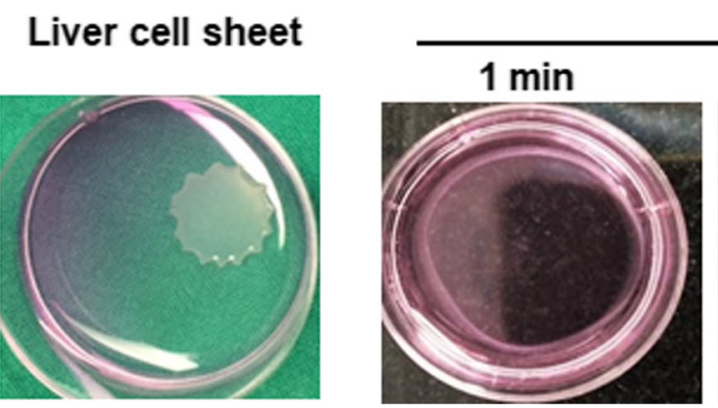

IPC sheet
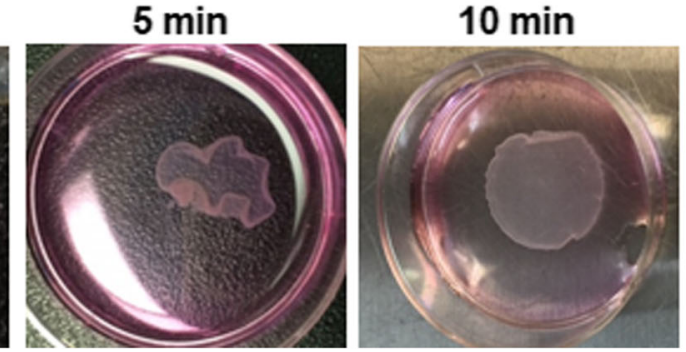

Fig. 1 Schematic description of the experimental procedure. a Preparation of insulin-producing cells from liver cells using transcription factors, process for the injection of insulin-producing cells (IPCS) through the portal vein, formation of IPC sheets on the temperature-responsive dish, and transplantation of IPC sheets onto the liver surface. $\mathbf{b}$ Procedure for harvesting of IPC sheets from the temperature-responsive dish. IPC or liver cells were cultured for 2 days and allowed to develop cell-cell interactions. At this point, the temperature was lowered to $25^{\circ} \mathrm{C}$ for $10 \mathrm{~min}$, and then, the cell sheet was allowed to float in the dish

the case of IPC sheets, the cell sheets cultured on the UpCell dish were harvested by reducing the temperature from 37 to $20^{\circ} \mathrm{C}$ (Fig. 1b) on day 3. For the in vitro assay, the IPC sheet was attached to the insert well with an 8$\mu \mathrm{m}$ pore size (SPL, Gyeonggi-do, Republic of Korea). Five days after the initial virus exposure, the IPC sheets and IPCs were harvested to analyze mRNA levels and insulin production; these values were compared to those obtained on culturing the IPCs on the monolayer culture dishes.

\section{Luciferase assay}

To optimize the virus transduction conditions, luciferase activity controlled by the insulin promoter was assessed. At day 2, cells were co-infected by adenovirus containing the firefly luciferase gene controlled by the rat insulin promoter (Ad-RIP-luciferase). At day 5 after initial virus exposure, the cells were harvested and lysed in passive lysis buffer (Promega, Madison, WI, USA). Luciferase activity was measured using the Luciferase Assay System (Promega) and normalized to protein levels. Luminescence was detected by a VICTOR2 2030 multilabel plate reader (Perkin Elmer, Waltham, MA, USA).

\section{Real-time quantitative PCR (qPCR)}

Total RNA was extracted from liver cells and IPCs on predetermined days using TRIzol reagent (Thermo Fisher Scientific). cDNA was synthesized from $1 \mu \mathrm{g}$ RNA template by an oligo-dT primer using a SuperScript III First-Strand Synthesis System (Thermo Fisher Scientific). Real-time PCR was performed using LightCycler 480 SYBR Green I Master mix (Roche Applied Science, Mannheim, Germany) in a LightCycler 480 II real-time thermal cycler (Roche Applied Science). The pancreatic endocrine gene-specific primer sets used are listed in 
Table 1. Gene expression was normalized to the glyceraldehyde 3-phosphate dehydrogenase housekeeping gene, and relative quantification was performed.

\section{Immunofluorescence staining}

Cells were fixed with $4 \%$ paraformaldehyde and permeabilized with $0.1 \%$ Triton X-100. After antibody blocking, primary antibodies were incubated overnight at $4{ }^{\circ} \mathrm{C}$. We used rabbit anti-insulin and mouse anti-glucagon (1: 1000; Abcam, Cambridge, UK), rabbit anti-PDX1, goat anti-PDX1, mouse anti-NEUROD1, rabbit anti-MAFA (1:200; Abcam), and mouse anti-albumin (1:100, Santa Cruz Biotechnology). For secondary fluorescence labeling, the cells were incubated with anti-rabbit IgG Alexa Fluor 488, anti-rabbit IgG Alex Fluor 555, anti-goat IgG Alex Fluor 488, anti-mouse Alexa 555, and anti-mouse Alexa 488 (1:200; Thermo Fisher Scientific). ProLong Gold antifade reagent containing DAPI (Thermo Fisher Scientific) was used to stain the nuclei and for mounting. The slides were visualized using the $\mathrm{EVOS}^{\ominus} \mathrm{FL}$ auto cell imaging system (Thermo Fisher Scientific). Under the microscope, the cells with red fluorescence were insulin or glucagon positive and blue fluorescence highlighted the nucleus and counted in 10 randomly selected fields per IPC sheet or IPC cells with total of 3 donors in each group. The results were presented as insulin- or glucagon-positive cells per 100 cells.

\section{Insulin and C-peptide analysis}

To measure the insulin and C-peptide contents in IPCs, cells were washed and lysed with RIPA lysis buffer [21]. Insulin and $\mathrm{C}$-peptide levels were measured using a commercial ultrasensitive insulin ELISA kit (80INSHUU-E01.1 ALPCO, Salem, NH, USA) and ultrasensitive C-peptide ELISA kit (10-1141-01, Mercodia, Uppsala, Sweden), respectively. Also, insulin secretion was measured in the culture medium of IPCs and IPC sheets by static incubation for 2 days in differentiation culture medium containing $5.5 \mathrm{mM}$ glucose. Insulin and Cpeptide contents were ascertained in cells from four different donors. Prior to glucose stimulation of the cells, any residual insulin released from the islets was removed by incubation in serum- and glucose-free RPMI 1640 medium. The tubes were kept at $37^{\circ} \mathrm{C}$ for $1 \mathrm{~h}$ with shaking, and then, the medium was completely removed by centrifugation and replaced with serum-free RPMI 1640 medium supplemented with $2.8 \mathrm{mM}$ glucose for $1 \mathrm{~h}$. Following collection of the medium, the cells were then incubated with serum-free RPMI 1640 containing $28 \mathrm{mM}$ glucose for an additional $1 \mathrm{~h}$. The supernatant from each sample was collected. The assays were performed in triplicate. The stimulation index was calculated as a ratio between the insulin secreted at high and low glucose media [22].

\section{Transmission electron microscopy (TEM)}

To analyze the granular ultrastructure, the cells were fixed with $1 \%$ glutaraldehyde and $1 \%$ PFA in $0.1 \mathrm{M}$ sodium cacodylate buffer $(\mathrm{pH} 7.2)$ at $4{ }^{\circ} \mathrm{C}$. Specimens were then fixed in $2 \%$ osmium tetroxide for $60 \mathrm{~min}$ at $4{ }^{\circ} \mathrm{C}$. Dehydration of the fixed samples was performed, and the samples were transferred to Lowicryl resin (Polyscience, Niles, IL, USA). Samples were then sectioned $(60 \mathrm{~nm})$ with an ultramicrotome (UltracutUCT, Leica,

Table 1 Primers used for qPCR amplification

\begin{tabular}{|c|c|c|c|}
\hline Gene & & Sequence $\left(5^{\prime} \rightarrow 3^{\prime}\right)$ & Product size (bp) \\
\hline \multirow[t]{2}{*}{ Insulin } & Forward & GCAGCCTITGTGAACCAACAC & 67 \\
\hline & Reverse & CCCCGCACACTAGGTAGAGA & \\
\hline \multirow[t]{2}{*}{ Glucagon } & Forward & CCCAAGATTTTGTGCAGTGGTT & 221 \\
\hline & Reverse & GCGGCCAAGTTCTTCAACAAT & \\
\hline \multirow[t]{2}{*}{ Somatostatin } & Forward & CTGTCTGAACCCAACCAGAC & 90 \\
\hline & Reverse & CAGCTCAAGCCTCATTTCAT & \\
\hline \multirow[t]{2}{*}{ PDX1 } & Forward & GCATCCCAGGTCTGTCTTCT & 140 \\
\hline & Reverse & CACTGCCAGAAAGGTITGAA & \\
\hline \multirow[t]{2}{*}{ Ngn3 } & Forward & GAAAGGACCTGTCTGTCGCT & 124 \\
\hline & Reverse & AGGGAGAAGCAGAAGGAACA & \\
\hline \multirow[t]{2}{*}{ NEUROD1 } & Forward & СCCTGTACACCCCTACTCCT & 92 \\
\hline & Reverse & GAGGCTTAACGTGGAAGACA & \\
\hline \multirow[t]{2}{*}{ Nkx6.1 } & Forward & CACACGAGACCCACTITITC & 76 \\
\hline & Reverse & CCGCCAAGTATTTTGTTTCT & \\
\hline \multirow[t]{2}{*}{ GAPDH } & Forward & GAAGGTGAAGGTCGGAGT & 226 \\
\hline & Reverse & GAAGATGGTGATGGGATTTC & \\
\hline
\end{tabular}


Wetzlar, Germany) and collected on nickel grids. Postembedding immunogold labeling was performed for insulin and glucagon labeling using the rabbit anti-insulin (Abcam), mouse anti-glucagon (Abcam), 5-nm colloidal gold conjugated to goat anti-rabbit IgG (Sigma-Aldrich), and 9-11-nm colloidal gold conjugated to goat antimouse IgG (Sigma-Aldrich). Following immunogold labeling, the sections were double-stained with $2 \%$ uranyl acetate for $20 \mathrm{~min}$ and lead citrate for $10 \mathrm{~min}$. The sections were then viewed using TEM.

\section{Transplantation of IPCs and IPC sheets to diabetic mice}

This study was reviewed and approved by the Institutional Animal Care and Use Committee (IACUC No. 2015-12-133) Asan Institute for Life Sciences. The committee abides by the Institute of Laboratory Animal Resources (ILAR) guide. All experiments related to animals were performed in accordance with the relevant guidelines and regulations. To develop insulin-dependent diabetic mouse model, male 8-week-old BALB/c nude mice were treated with $180 \mathrm{mg} / \mathrm{kg}$ STZ (Santa Cruz Biotechnology) dissolved in $0.1 \mathrm{M}$ citrate buffer ( $\mathrm{pH} 4.5)$. After inhalational anesthesia with isoflurane, the abdomen of each mouse was swabbed with Betadine and an approximately $1.5-\mathrm{cm}$ incision was made. Once the portal vein was exposed, it was flat enough to allow a 30 -gauge needle to be inserted without restriction. Slight traction was kept on the pancreas near the vein bed with a sterile Qtip to create tissue tension for injection through the needle. A syringe was attached to the 30-gauge needle, and a suspension of IPCs $\left(1 \times 10^{6}\right.$ cells in $100 \mu \mathrm{L}$ of phosphate-buffered saline) was released into the portal vein for $1 \mathrm{~min}$. We did not routinely inject more than $10^{6}$ cells because the injection of greater numbers of cells often was lethal to the mice. Using Q-tips, the injection site was pressed gently for at least $5 \mathrm{~min}$ to stop any bleeding. The abdomen was closed and treated with Betadine.

Before cell sheet transplantation, liver capsules at the intended site were removed by swabbing the liver surface. An IPC sheet with CellShifter ${ }^{\mathrm{rm}}$ was placed on the liver surface, and the CellShifter ${ }^{\mathrm{Tw}}$ was removed after 5 min. One IPC sheet contained approximately $10^{6}$ cells. We transplanted one cell sheet for the biodistribution study to match the cell number with the portal vein injection group. To increase the efficacy of IPC sheets, we transplanted one IPC sheet or three IPC sheets onto the liver of the diabetic mice for efficacy evaluation. Blood glucose was monitored after transplantation using a Codefree blood glucose monitoring system (SD Biosensor, Suwon, Republic of Korea). To confirm human insulin secretion after transplantation, we collected blood serum on the predetermined date and evaluated human serum insulin using an ultrasensitive insulin ELISA kit (80-INSHUU-E01.1 ALPCO, Salem, NH, USA).

\section{Cell labeling and imaging ex vivo and in vivo}

IPCs were labeled with Qdot 800 (Qtracker 800; Molecular Probes, Inc., Eugene, OR, USA). In vivo optical imaging was conducted using an IVIS Spectrum imaging system (Caliper Life Science Inc., Waltham, MA, USA). Images were acquired using an excitation and emission wavelength of 430 and $800 \mathrm{~nm}$, respectively. Fluorescence was quantified as the sum of all detected photon counts per second within a constant region of interest for each transplant site (in vivo). At 7 days after transplantation, the mice were sacrificed and the livers, kidney, spleen, pancreas, and lung were harvested. The fluorescence in each organ was detected (ex vivo image).

\section{Liver toxicity}

Blood samples were collected from the retro-orbital sinus. Hepatic toxicity measurements included ALT and aspartate aminotransferase (AST) in the blood serum at 1,2 , and 5 days after transplantation. Serum ALT and AST levels were analyzed using a model 7180 automatic biochemistry clinical analyzer (Hitachi, Tokyo, Japan).

\section{Histological analysis}

After sacrificing the mice on days 7 and 14, the livers were removed and fixed with $4 \%$ formalin. A paraffin block was prepared and cut into 4- $\mu \mathrm{m}$ sections. The tissue slides were deparaffinized and dehydrated. Samples subjected to antigen retrieval were blocked with $3 \%$ bovine serum albumin. Immunohistochemistry was performed using primary antibodies for rabbit anti-PDX1 (dilution 1:200, Abcam) and rabbit anti-insulin (dilution 1:1000, Abcam). To confirm neovascularization in transplanted site, we also stained liver tissue using CD31 (dilution 1:1000, Abcam). A DAB Detection Kit (REAL EnVision detection system, DAKO, Glostrup, Denmark) was used for immunohistochemistry. To perform hematoxylin and eosin staining, samples were deparaffinized and dehydrated, followed by staining with hematoxylin (Sigma-Aldrich) and eosin (Sigma-Aldrich).

\section{Statistical analyses}

The data are presented as the mean \pm standard deviation, with the number of samples indicated in the figure legends. The statistical significance of the differences between multi-groups was analyzed with one-way ANOVA test and by determining the differences between the means with Tukey's post hoc test. The statistical significance of the difference between the two groups was analyzed with Student's $t$ test. $P<0.05$ indicated a statistically significant difference. 


\section{Results}

\section{IPC sheet fabrication}

To generative insulin-producing cells, we isolated liver cells from human liver tissues using collagenase. After proliferation, the liver cells were transduced with PDX1 and NEUROD1 for 2 days, followed by replacement of the medium with MAFA-containing medium for 3 days for trans-differentiation. The purpose of this experiment was to compare differentiation in vitro and diabetic control between IPCs and IPC sheets. A schematic summary of the protocol is summarized in Fig. 1a. We simultaneously transduced PDX1 and NEUROD1 for 2 days for both IPCs and the IPC sheets in a conventional culture dish. Then, we harvested cells and re-plated the cells in culture dishes in the presence of MAFA for 3 days. To fabricate the IPC sheets, we harvested and re-plated the cells in temperature-responsive dishes. MAFA was transduced in the same manner as the two-dimensional culture condition. To assess differentiation in vitro, cell sheets were harvested from UpCell dishes by reducing the temperature from 37 to $20^{\circ} \mathrm{C}$ (Fig. 1 b) at day 3. Each IPC sheet was reattached to the insert well for the in vitro assay. Five days following initial virus exposure, each of the IPC sheet was harvested to analyze mRNA levels and insulin production compared to IPCs cultured on the monolayer culture dish. In case of transplantation, we changed the medium at day 3 and collected IPC sheets for transplantation on the liver surface by reducing the temperature at day 5 . We also harvested IPCs from culture dish at day 5 and injected the cells through the portal vein.

\section{Characterization of human liver cells}

Human liver cells were isolated from liver tissues of 38 donors, including three type 1 diabetes patients. All donors or guardians provided written informed consent for the collection of all samples and subsequent analysis. The donor characteristics of the 38 human livers are provided in the supplement. Mean donor age was $50.2 \pm 16.1$ years (range 17-79). The primary culture of human liver cells exhibited a heterogeneous phenotype and proliferated efficiently in culture for more than 10 passages. After the 3rd passage, spindle and fibroblast-like cells predominated, while round-shaped cells gradually disappeared (Fig. 2a). Cells proliferated constantly, and a lag time was observed at the 4th or 5th passage (Fig. 2b). Liver cells differentiated into their osteogenic and adipogenic lineages. Osteogenic induction was visualized by Alizarin Red S staining (Fig. 2c, right), and adipogenic differentiation was observed by the presence of lipid droplets detected by Oil Red O staining (Fig. 2c, left). To analyze phenotype, flow cytometry was performed on isolated liver cells at early (passage 1-2), mid (passage 6-7), and late (passage 12-13) passages (Fig. 2d and Supplementary Table 2). Cells isolated from human liver tissues were positive for CD29, CD90, and CD105, whereas they were negative for CD31 and CD45 at all passages. The prevalence of CD73-positive cells exceeded $90 \%$ at all time points and increased with continued passaging. Cells were also negative for human leukocyte antigen-DR isotype (HLA-DR). We also confirmed the expression of hepatic markers in liver cells by flow cytometry and immunocytochemistry. Albumin was partially expressed at the initial stage $(19.8 \pm 10.5)$, but isolated liver cells in culture displayed decreased albumin expression at late passages $(0.5 \pm 0.2)$.

\section{Expression of ectopic transcription factors using adenoviral vectors}

To determine the optimal dose for the transduction of liver cells using adenoviral vectors, liver cells at passage 6 from three different donors were infected with adenovirus expressing green fluorescent protein under the control of a cytomegalovirus promoter (Ad-CMV-GFP) at various multiplicities of infections (MOIs) from 50 to 1000. Flow cytometry analysis was performed 2 days after infection to determine the number of GFP-positive cells. At MOI 50 , more than $50 \%$ of cells were transduced with Ad-CMV-GFP (Fig. 3a). The intensity of GFP fluorescence was dose-dependently increased, and the number of GFP-positive cells at MOI 200 was greater than $90 \%$. Immunocytochemistry confirmed ectopic gene expressions of PDX1, NEUROD1, and MAFA in the nuclei of liver cells using various MOIs (Figure S1) for 2 days. At MOIs of 250,500 , and 1000 , over $90 \%$ of cells were positive for PDX1, NEUROD1, and MAFA, respectively. Also, we confirmed co-expressions of PDX1, NEUROD1, and MAFA in nuclei after liver cells were transduced with Ad-CMV-hPDX1 (MOI 500) and Ad-hNEUROD1 (MOI 250) for 2 days and consequently with Ad-CMV-MAFA (MOI 50) for 3 days. PDX1 and NEUROD1 were co-expressed in most cells, while MAFA was partially expressed (Fig. 3b).

The cooperative action of various transcription factors is required for efficient trans-differentiation of adult cells to IPCs. The MOI of each factor was titrated to result in maximal insulin promoter activity, which was determined by luciferase assay and insulin gene expression analysis, with minimal adverse effects on gene-infected cell viability. To determine the optimal dose for the transduction of liver cells using adenoviral vectors, liver cells at passage 6 were infected with Ad-CMV-hPDX1 and Ad-hNEUROD1 at various MOIs for 2 days and consequently with Ad-CMV-MAFA at MOI 50 for 3 days. As the MOI of PDX1 increased, luciferase activity also increased (Fig. 3c). However, an MOI of PDXI 


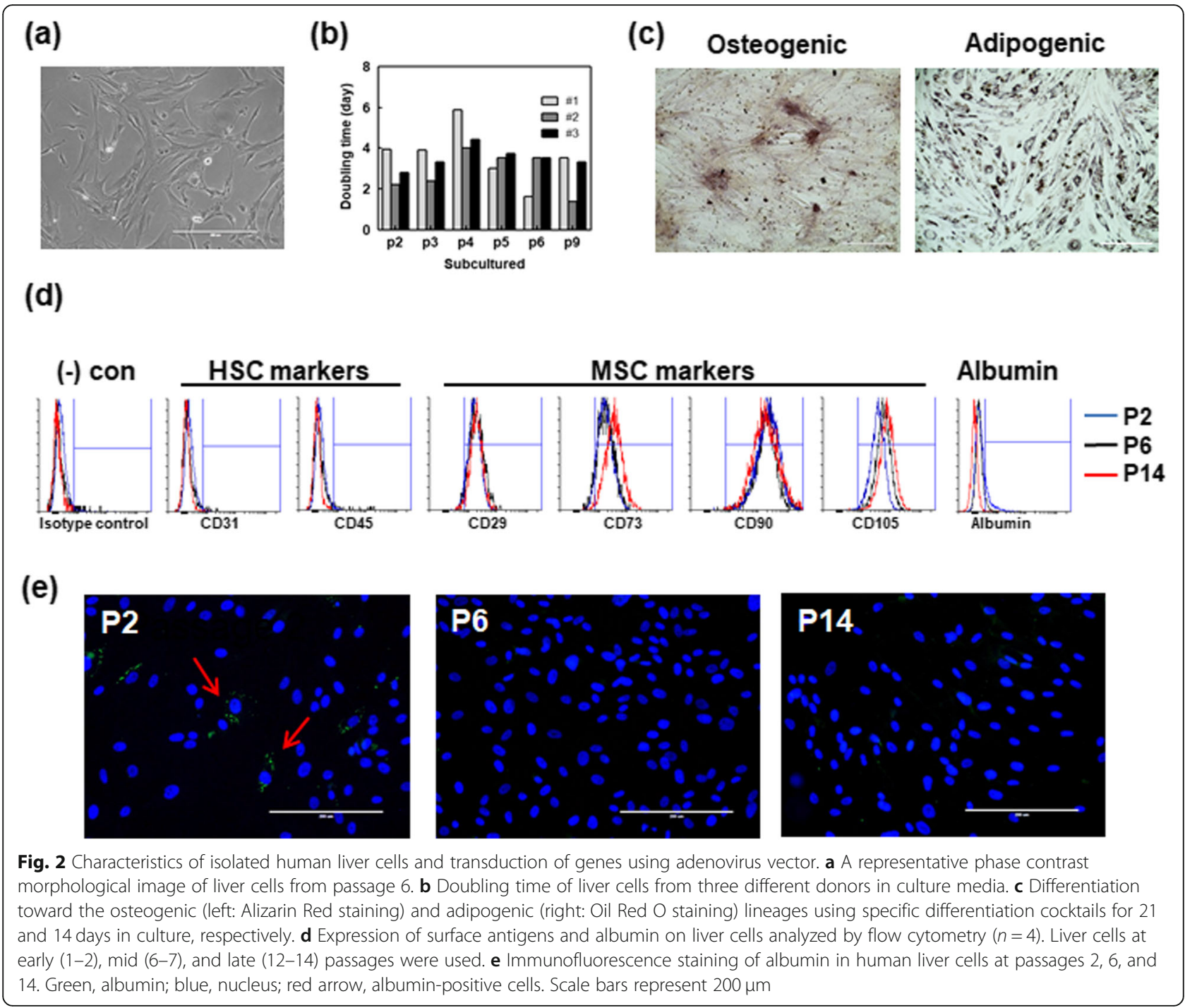

greater than 500 resulted in high rates of cell death. Combined treatment of the three different transcription factors produced the highest luciferase activity compared with that in cells treated with PDX1 alone or with PDX1/NEUROD1. Luciferase activity assessed in liver cells from three different donors showed a similar pattern. Also, we confirmed insulin gene expression after transduction with ectopic genes. The combination of PDX1/NEUROD1 and MAFA transcription factors increased the intensity of insulin mRNA levels compared with the levels in cells treated individually with PDX1, NEUROD1, or MAFA, or with PDX1/NEUROD1. Insulin gene expression was substantially increased (26-fold) in adult human liver cells co-infected with the three recombinant adenoviruses compared with the expression in non-treated liver cells (Fig. 3d). Based on these results, the MOIs of PDX1, NEUROD1, and MAFA were optimized to 500,250 , and 50 , respectively.
Confirmation of the trans-differentiation of liver cells to IPCs

Insulin production was assessed by measuring insulin contents in IPCs and in undifferentiated liver cells. As shown in Fig. 3e, the insulin content in IPCs was significantly increased in four different donors compared to the content in liver cells. Particularly, liver cells from donor number D3 were isolated from a type 1 diabetes patient. To confirm the trans-differentiation of liver cells to IPCs, immunohistochemistry and insulin contents were assessed by incubation of adult liver cells for 5 days after initial exposure to viral treatment. Compared to IPCs, insulin-positive cells were identified in the IPC sheets at a higher rate, whereas glucagon-positive cells were more prominent in IPCs (Fig. 3f). But to determine the granular protein composition, immunogold labeling of insulin and glucagon in IPCs was followed by transmission electron microscopy (TEM) examination 


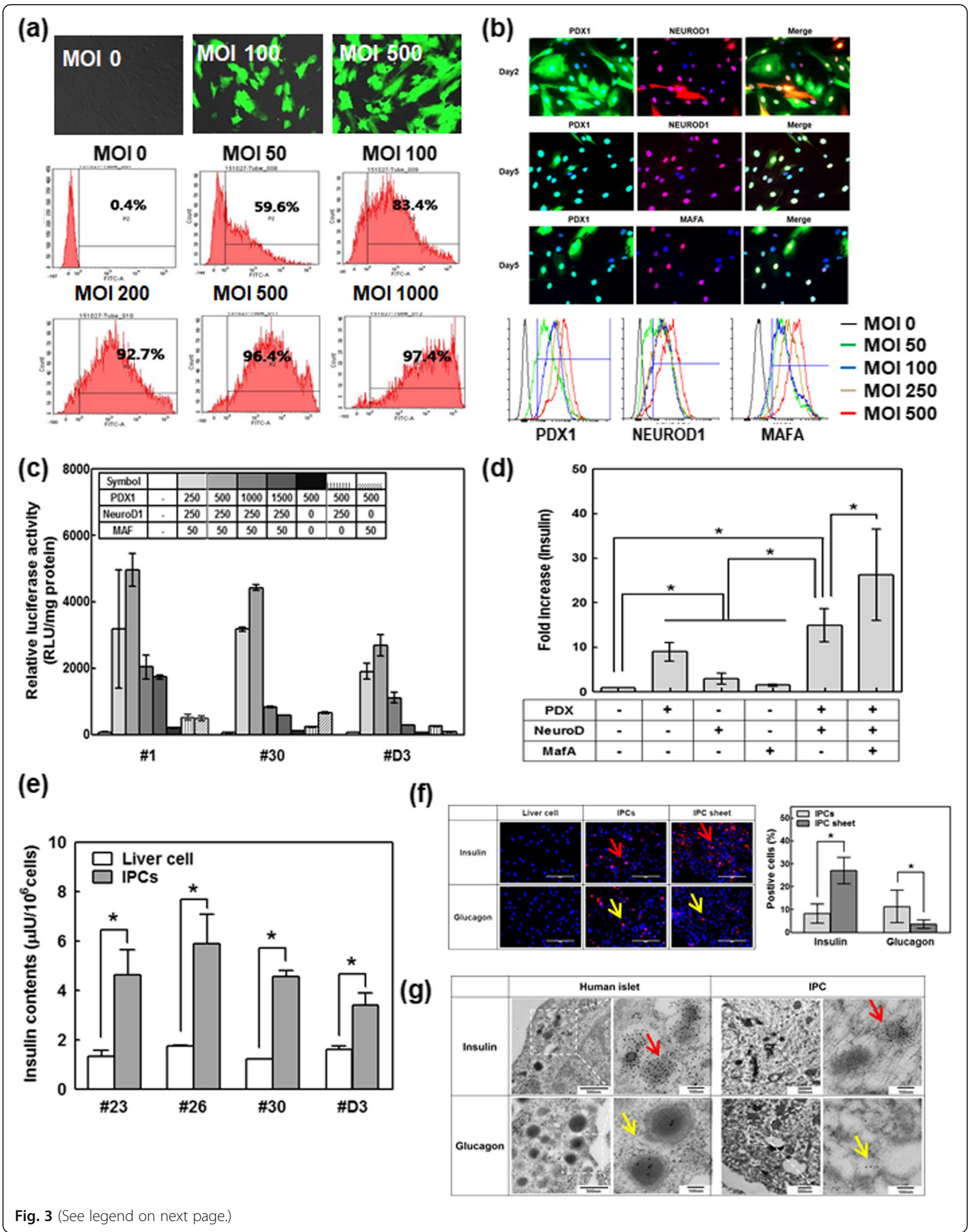




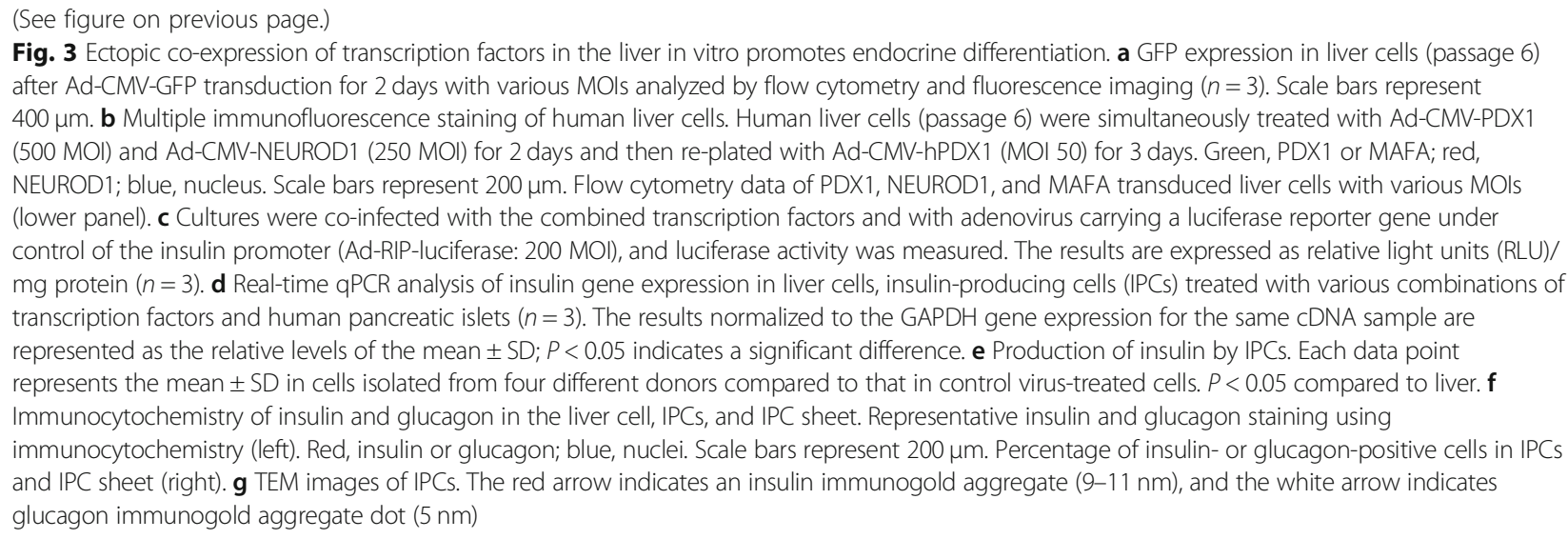

(Fig. 3g). Insulin protein aggregates were observed in IPCs, while glucagon protein was spread in the cytosol in very small amounts. While we confirmed insulin expression in IPCs by TEM and insulin production in an ELISA assay, the insulin level was much lower than that in natural human islets.

\section{Cell sheet formation enhances the differentiation function of IPC}

To compare the trans-differentiation of IPCs under different culture conditions, the mRNA levels of endocrine hormone and pancreatic transcription factors were determined after 5 days of culture. As shown in Fig. 4a, IPCs expressed endocrine hormones, including insulin, glucagon, and somatostatin, and pancreatic-specific genes, including PDX1, NEUROD1, MAFA, NGN3, NKX2.2, NKX6.1, and glucose transporter 2 (GLUT2) compared to IPCs cultured on conventional culture plates. In particular, the insulin mRNA level of IPCs cultured with the sheet structure was significantly higher than that of IPCs, whereas IPCs in the sheet structure did not have detectable levels of glucagon mRNA. Similarly, pancreatic transcription factors related to beta cell trans-differentiation were higher in IPC sheets than in single cell cultures. This finding suggested that sheet formation can induce trans-differentiated liver cells in the beta cell lineage but represses unwanted transdifferentiation into the alpha cell lineage. Additionally, insulin and $\mathrm{C}$-peptide production and insulin secretion were significantly increased in IPC sheets compared to IPCs (Fig. 4b, c). To further examine physiological insulin secretion, we evaluated the level of insulin secretion at two different glucose concentrations $(2.5 \mathrm{mM}$ and 25 $\mathrm{mM})$. Although the secretion in IPC sheets tended to be slightly higher than that in IPCs, the stimulation index (insulin release at high glucose/low glucose) was not significantly different between IPCs and IPC sheets (Fig. 4e).

\section{Transplantation of IPC sheet on liver surface and IPCs through the portal vein}

The drug STZ is known to induce diabetes. For the mouse model of diabetes, STZ $(180 \mathrm{mg} / \mathrm{kg})$ was administered by single and intraperitoneal injection. When blood glucose levels were $\geq 300 \mathrm{mg} / \mathrm{dL}$ for more than 1 week, mice were either transplanted with an IPC sheet onto the liver surface or injected with IPCs through the portal vein. Figure 5a illustrates the process for IPC intraportal injection (upper) and cell sheet transplantation onto the liver surface (lower) in the animal study. A single cell sheet $\left(10^{6}\right.$ cells) was transplanted onto the liver surface to transplant the same number of cells as were administered by intraportal injection. Five of 25 mice injected $10^{6}$ IPCs died during portal vein injection or from postoperative complications, while all mice survived sheet transplantation.

To track transplanted cells, cells were labeled with Qdot 800, which supports intense fluorescence under various biological conditions and less auto-fluorescence in tissue [23]. The fluorescent IPC signal was detected in the region of the liver in transplanted mice at days 2 and 7 , while a weak fluorescent signal was detected in the intraportal injection group on day 2. Mice were sacrificed, and internal organs were imaged ex vivo at 7 days post-transplantation. The greatest fluorescent signal was detected in the liver of the sheet-transplanted group (Fig. 5b, c).

We examined the therapeutic effects of IPC sheets in comparison to IPC intraportal injection for diabetes in nude mice. To confirm human insulin secretion after transplantation, human insulin levels were evaluated on days $3,14,21$, and 28 (Fig. 5d). The mice transplanted three IPC sheets showed higher insulin levels than IPCinjected mice. After transplantation, a decrease in blood glucose levels from diabetic mice was observed at first week in all IPC and IPC sheet groups. Although an increase in blood glucose levels was observed in both the IPC injection and cell sheet groups, the mice 


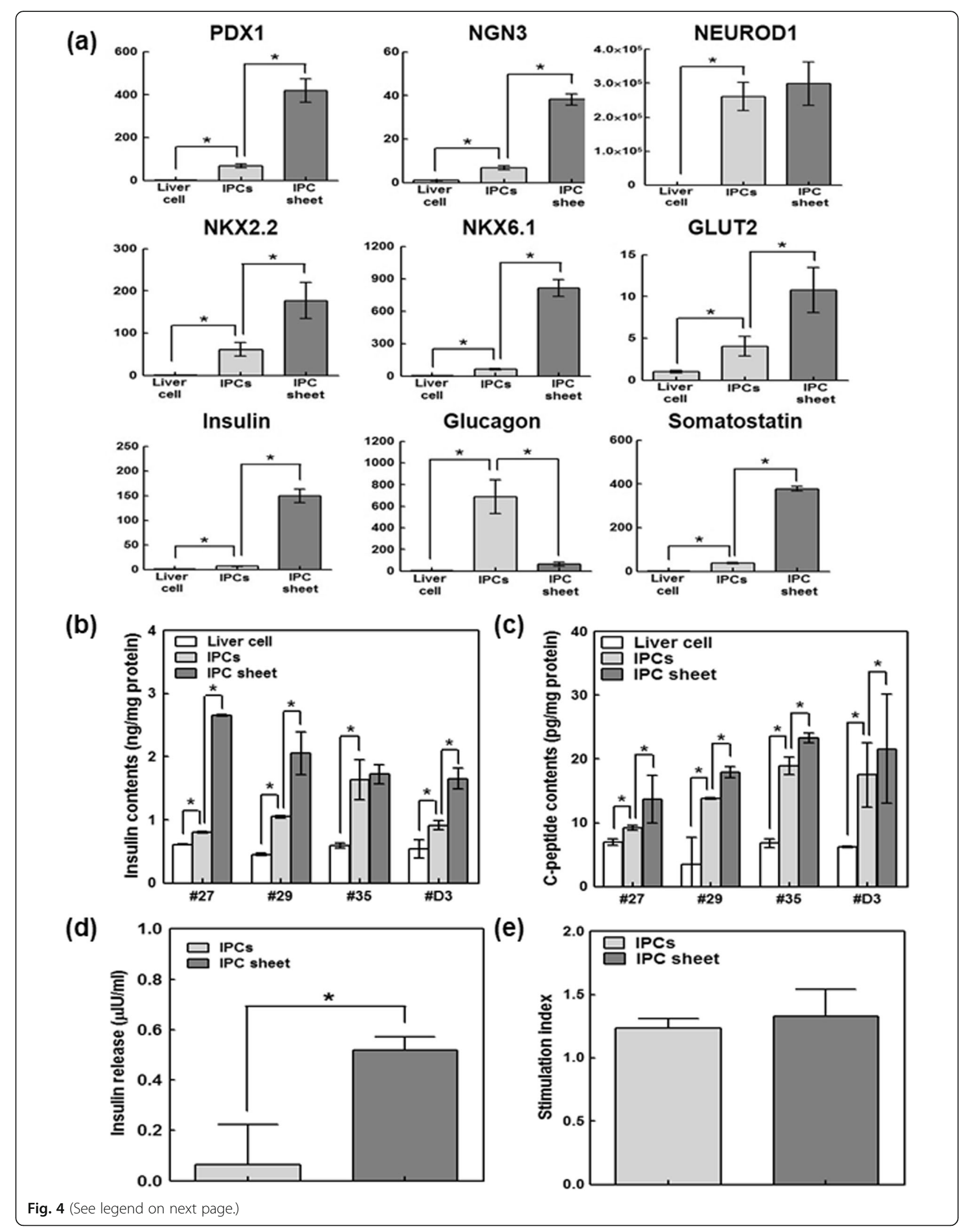


(See figure on previous page.)

Fig. 4 Comparison of mRNA expression and insulin production between insulin-producing cell (IPC) sheets and IPCs cultured on a conventional cell culture plate. a Real-time qPCR analysis of gene expression in liver cells and IPCs. IPCs were confirmed to express endocrine hormones, including insulin, glucagon, somatostatin, and pancreatic-specific genes, including PDX1, NGN3, NEUROD1, NKX6.1, and glucose transporter 2, compared to those in liver cells. The results normalized to GAPDH gene expression for the same cDNA sample are represented as the relative levels of the mean \pm SD; $P<0.05$ indicates a significant difference. $\mathbf{b}$ Insulin and c C-peptide contents and $\mathbf{d}$ insulin secretion in IPCs and IPC sheets after 5 days of culture. e Glucose stimulated insulin secretion index. The stimulation index was calculated as a ratio between the insulin secreted at high and low glucose media

transplanted three IPC sheets showed the lowest blood glucose levels during the observation period. Additionally, mice transplanted with the one or three IPC sheets showed an increase in body weight, while the single cell injection and diabetic control groups showed decreased body weights (Fig. 5e). After 1, 2, and 4 weeks of transplantation, PDX1 and insulin-expressing cells were detected by immunohistochemistry staining on the liver surface only in the IPC sheet group (Fig. 5f). Also, we confirmed CD31-positive cells to detect neovascularization in the transplantation site. Abundant blood vessels were shown around the transplanted cell sheet, and some CD31-positive cells were also found in the IPC sheets (Fig. 5g).

\section{Liver toxicity after transplantation and histology}

Liver function and histological examinations were performed to evaluate liver toxicity after intraportal injection or cell sheet transplantation of IPC. One day after cell injection through the portal vein, ALT and AST increased rapidly and then recovered gradually (Fig. 6a). In the IPC sheet group, ALT and AST levels were as low as one third of the value in the injection group. At 7 and 14 days after transplantation, the liver surface of transplanted animals was visually observed (Fig. 6b). In the PV injection group, white necrotic tissue was observed in many parts of the liver margin. Although this was completely recovered after 2 weeks, a morphological change was also observed. In contrast, these necrotic tissues or morphological changes were not observed in the IPC sheet group. Histological evaluation showed similar results (Fig. 6c). In the injection group, the necrosis structure was confirmed. No necrotic region was observed in the sheet group, and the sheet adhered well to the liver surface.

\section{Discussion}

Transplantation of autologous insulin-producing cells (IPCs) may be an ideal diabetic treatment for overcoming the limitations of current pancreas and islet transplantation, including the shortage of donors, immune reactions of the allograft, and low graft survival [24]. Various techniques and an alternative cell source have been actively reported for the development of new IPCs using differentiation from stem cells $[25,26]$, the proliferation of existing adult $\beta$ cells [27], and reprogramming of adult somatic cells [28, 29]. A recent report showed that cells isolated from the liver have high differentiation potential for the pancreatic lineage because the liver has the same origin as the pancreas.

In this study, we isolated and used liver cells according to the previous reported method in Sarah et al. Adherent cells isolated from the liver acquired mesenchymal-like characteristics and considerable cellular plasticity, as has previously been reported [9]. According to the results of genetic lineage-tracing of liver cells, cells isolated from the liver were partially positive for hepatic markers such as albumin and AFT and simultaneously positive for MSC markers. However, they were negative for hematopoietic (CD45, CD31) and hepatic progenitor markers (CK19, EpCAM) [9]. Authors said that the isolated liver cells can proliferate and obtain mesenchymal characteristics and cellular plasticity through EMT in in vitro cultures. Similarly, in this study, albuminpositive cells were identified through immunocytochemistry staining and flow cytometry at the initial stage of isolation, and it was also confirmed that they were positive for MSC surface markers and possessed differentiation ability.

Numerous studies have been conducted in which differentiation of insulin-producing cells was effected by inducing the expression of transcription factors such as PDX1, NGN3, MAFA, and PAX4, which play important roles in pancreatic development [30,31]. Recently, Ferber et al. showed that mature $\beta$ cell-like characteristics were induced when three pancreatic transcription factors, PDX1, PAX4, and MAFA, were sequentially supplemented in a direct hierarchical manner [14]. It is important that transcription factors are turned on and off at appropriate times for determining cell fate. PDX1 alone has little activity or it induces other pancreatic cells; however, it becomes a potent factor when it interacts with NEUROD1 [32, 33]. Another important transcription factor for $\beta$ cell-specific differentiation is MAFA [34-37]. Thus, we used PDX1, NEUROD1, and MAFA to induce IPC from liver cells. Based on these previous studies, PDX1 was essentially used to induce trans-differentiation from mesoderm to endoderm. In addition, NEUROD1, which can simultaneously induce endoderm while enhancing the effect of PDX1 by binding to the same site as PDX1, was simultaneously added. In particular, as the switch from MAFB to MAFA 


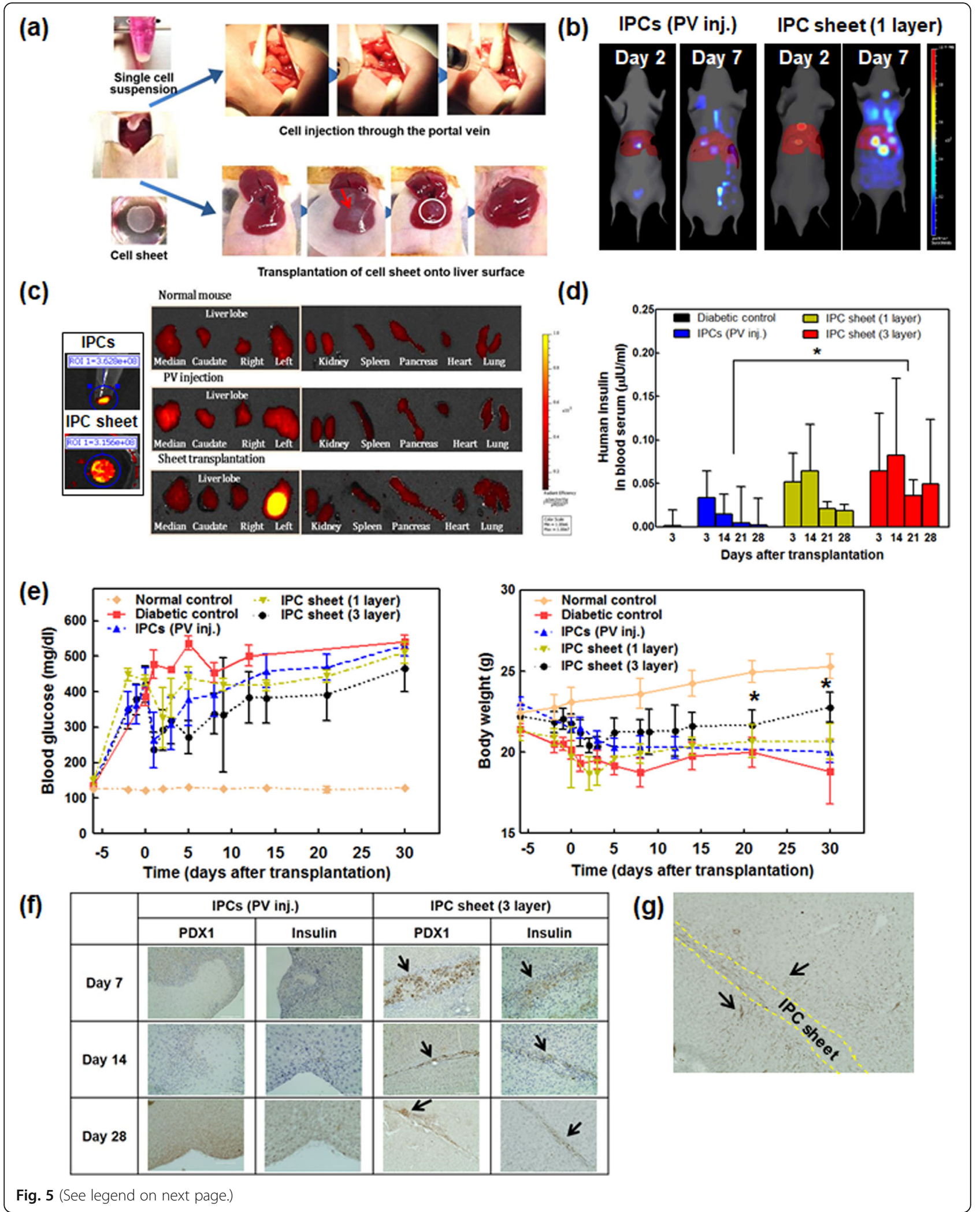


(See figure on previous page.)

Fig. 5 Comparison of transplantation efficiency between transplantation of insulin-producing cell (IPC) sheets (one or three sheets) on the liver surface and injection of IPCs through the portal vein. a Photographs of experimental protocols of IPC portal vein injection (upper) and IPC sheet transplantation on the liver surface of immune-deficient diabetic mouse. b Distribution of transplanted or injected IPCs in mice. The distribution of transplanted IPCs in recipient mice was examined with an in vivo imaging system. Optical imaging of IPC labeled Qdot 800 in vivo and ex vivo. Fluorescence color images were processed using Living Image V.3.2. A grayscale body image was collected and overlaid by a pseudo-color image representing the spatial distribution of the detected photons. c Fluorescence images of IPCs and IPC sheet before transplantation (left). Seven days after treatment, the liver, kidney, spleen, pancreas, heart, and lung were harvested, and ex vivo fluorescent images were acquired (right). $\mathbf{d}$ Human insulin levels in blood serum from mice transplanted with one or three cell sheets and PV injected. Diabetic mice without transplants were negative controls. $N=4$ or 5 . The asterisk symbol (*) indicates a significant increase in the insulin level of IPC sheets (three layers) upon IPC injection at each time point; $P<0.05$. e Therapeutic effects of insulin-producing cell (IPC) sheet transplantation in diabetic nude mice. Two weeks before transplantation, mice were induced with insulin-dependent diabetes using streptozotocin (180 mg/mL). At day 0, diabetic nude mice were transplanted with three IPC sheets or injected with $10^{6} \mathrm{IPC}$ through the portal vein. Diabetic nude mice and wild-type mice were used as negative and positive controls, respectively. At different time points, non-fasting blood glucose levels and body weights were measured in sheet transplanted on liver surface, portal vein injected IPCs, and diabetic control $(n=5)$. The asterisk $\left(^{*}\right)$ indicates a significant increase in body weight upon IPCs; $P<0.05$. $\mathbf{f}$ Immunohistochemical analyses of PDX1and insulin in the liver at 7, 14, and 28 days after transplantation of IPCs and IPC sheets. Arrows indicate positive cell staining. Original magnifications are $\times 200$ (PDX1) and $\times 400$ (insulin). g Immunohistochemical analyses of CD31 in the liver at 28 days after transplantation of IPC sheets. Arrow indicated positive cell staining. Original magnifications are $\times 200$

expression is essential for maturation of beta cells, $M A F A$ was introduced 2 days after the start of differentiation to improve insulin production through maturation of IPC. PDX1 at an MOI 500 was used as a key factor because PDX1 plays a crucial role in pancreatic organogenesis and beta cell function. The MOI of NEUROD1 and $M A F A$ was optimized based on insulin promoter activity, insulin gene expression, and minimal adverse effects on infected cell viability. This combination increased the intensity of insulin promoter activity and mRNA level of insulin genes compared to that in cells treated with either PDX1 or NEUROD1, MAFA alone. In this study, PDX1 and NEUROD1 were added at the same time, and MAFA was sequentially induced 2 days later to maximize trans-differentiated cell maturation, as indicated by increased insulin gene expression. Insulin protein was confirmed to be expressed by immunohistochemistry, TEM image, and ELISA. Unlike fully mature beta cells, granule formation was not complete, but some aggregates of insulin protein were identified in TEM image. However, glucagon did not form an aggregate and was distributed in the cytosol to a small degree.

It is known that cell-cell interaction of islets is important for insulin production and secretion [38, 39]. In our study, when cell sheets were formed, insulin gene expression and protein production were significantly increased. Also, several transcription factors were significantly increased in the cell sheet group. Interestingly, the expression of glucagon was dramatically reduced in the cell sheet group. In previous reports, Nkx6.1 reduces the expression of the glucagon gene, which explains why these transcription factors in the cell sheet group decreased glucagon expression and thus increased the purity of insulin-producing cell differentiation [40]. Insulin and C-peptide production and insulin secretion also significantly increased in the sheet group. Although the cell sheet's ability to induce differentiation in IPC was confirmed in this study, further studies are required to determine the mechanisms underlying cell sheet formation and IPC differentiation and maturation.

A cell sheet-based tissue engineering approach has attracted attention in cell transplantation therapy because of its potential to deliver a large number of cells to the desired organ without surgical procedures $[15,41$, 42]. Cell sheets maintain adhesive protein layers that facilitate attachment to other tissues. The cell sheet technique also makes the delivery of target molecule safe. In the successful clinical trial of intraportal islet transplantation by Shapiro et al., islet transplantation was exclusively conducted via the portal vein [17, 43, 44]. When the islet is administered directly through the portal vein, many cells engraft in the liver through smaller venues, and the liver can supply sufficient blood in a nearphysiological insulin delivery environment. However, several concerns remain regarding intraportal islet infusion, including procedure-related complications, bleeding, hepatic hypertension, thrombosis, and instant blood-mediated inflammatory reaction [16]. Various alternative sites for successful islet engraftment have been proposed for the islet or IPC, including the kidney capsule, omentum, skin, and cornea. Subcutaneous engraftment has also been proposed. Recently, Alejandro et al. reported that a patient who underwent islet transplantation on the omentum showed stable glycemic control without exogenous insulin and episodes of hypoglycemia at 12 months [45]. Although some locations may be advantageous in experimental models, their feasibility and translation into clinical settings are limited [46]. An ideal transplantation site should include a sufficient blood supply without any surgical risk. The liver is ideal for cell transplantation because of the high blood supply, near-physiologic insulin delivery environment, and long clinical application history. If the IPCs' construct can be directly transplanted onto the liver surface, rather than 


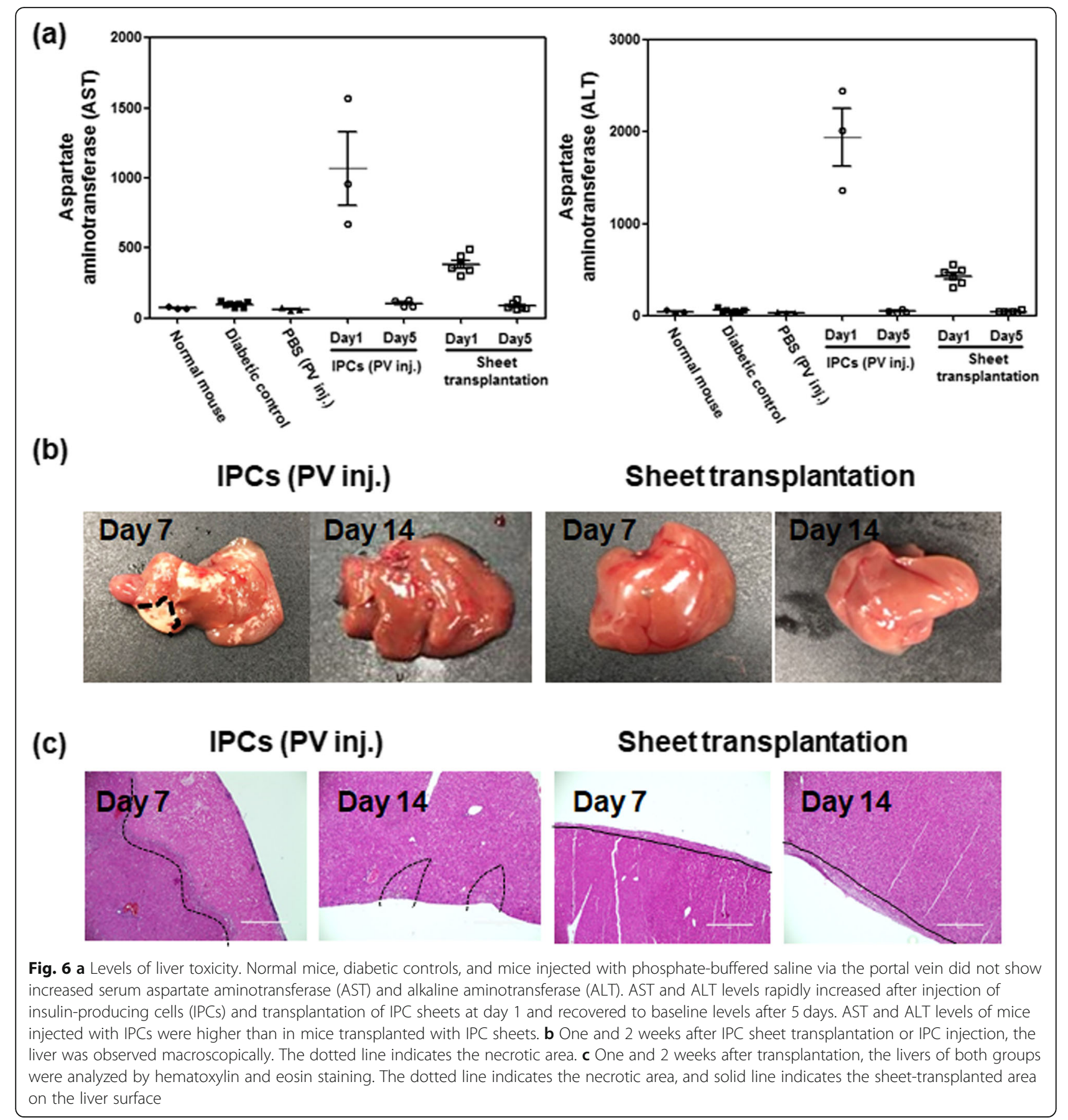

via portal vein injection, this may be an ideal transplantation technique for ensuring safety and increasing survival and near-physiological insulin delivery. In this study, we confirmed that the IPC sheet improved the delivery efficacy of IPCs in the liver and decreased the risk of PV injection. Additionally, IPC sheet formation may enhance the differentiation function of IPCs in vitro by maintaining cell-cell interactions. To identify the potential of clinical applications for IPC sheet transplantation, we assessed not only glycemic control efficiency but also operative feasibility, biodistribution, and liver toxicity, compared to the IPC intraportal injection technique. To develop an insulin-dependent diabetic mouse model, nude mice were treated with $180 \mathrm{mg} / \mathrm{kg}$ streptozotocin once. In this study, cells were isolated from human liver tissues and transduced with the genes for human transcription factors PDX1, NEUROD1, and MAFA to induce their differentiation into IPCs. Mice cells could not be used because we have not evaluated the availability of human transcription factors in mouse cells in any 
previous study. Therefore, athymic nude mice were used as the diabetic animal model to control immunity for human cell transplantation.

There are a million cells per IPC sheet, which has the same cell count for the IPC PV injection group. Although cell sheet formation enhanced the differentiation of IPCs in vitro, there were no significant differences in vivo between the mice injected with $10^{6}$ IPCs and those transplanted with the IPC sheet. This is because the number of differentiated cells is insufficient for regulating blood glucose levels when a single cell sheet is used. However, increasing the number of IPC sheets (three layers) could decrease the glucose levels and increase the body weight. The same has been confirmed in case of human insulin secretion in blood. Mice transplanted with three IPC sheets showed higher insulin levels than did IPC-injected mice. It is important to improve the differentiation efficacy of IPCs, and the delivery of large quantities of cells to the target site in a nontoxic manner can significantly improve their function. Although sheet formation did not completely regulate blood glucose levels when the same number of cells was used, the method was advantageous as the cell number could be increased if necessary. It is difficult to introduce more than a certain number of cells through portal vein injection, which is the method used in clinical practice, owing to the risks of serious side effects, such as embolisms. Also, immunohistochemical analyses showed that IPC sheet-transplanted livers stained positively for PDX1 and insulin at 1,2 , and 4 weeks posttransplantation.

After injecting the IPC suspension via the portal vein, and transplantation of the IPC sheet onto the liver of diabetic nude mice, cell biodistribution was assessed by in vivo/ex vivo fluorescence image tagging Qdot. The IPCs were detected in the liver in the cell sheettransplanted region of mice at days 2 and 7, while the intraportal injection group showed only a weak signal at day 2 . This was confirmed by ex vivo fluorescence image and histology.

Increasing transplantation efficiency and reducing toxicity are important factors for clinical application. When we injected $10^{6}$ differentiated IPCs through the portal vein, $80 \%$ of animals survived. In the preliminary study, mice transplanted with $1.5 \times 10^{6}$ and $2 \times 10^{6}$ IPCs died at rates of $40 \%$ and $90 \%$ during surgery, respectively (data not shown). In this study, when high doses of cells $\left(1.5 \times 10^{6}\right.$ and $\left.2 \times 10^{6}\right)$ were administered through the portal vein, most animal deaths occurred in the middle of surgery or within tens of minutes of surgery. In general, portal vein thrombosis rates in humans and thromboembolisms and subsequent mortality in murine models are reported to occur due to injection through the portal vein [47]. Death of high-dose cells through PV injection is caused by thromboembolisms formed by excess cells. However, no mice transplanted with 1,3 , or 5 layers of the IPC sheet died as a consequence of the operation. Mice injected with the IPCs through the portal vein showed liver toxicity and histologic damage to many parts of the liver margin. However, the IPC sheet showed no significant liver toxicity in our study. These results showed that directly transplanting the IPC sheet onto the liver surface is expected to significantly lower the risks related to current intra-portal vein injection, which include thrombosis, bleeding, and liver toxicity.

In conclusion, cell sheet formation enhanced the differentiation function and maturation of IPC in vitro. Additionally, parameters for clinical application such as distribution, therapeutic efficacy, and toxicity were favorable. The cell sheet technique may be used with IPCs derived from various cell sources in clinical applications.

\section{Supplementary Information}

The online version contains supplementary material available at https://doi. org/10.1186/s13287-020-02080-0.

\section{Additional file 1.}

\section{Abbreviations}

Ad-CMV-GFP: Adenovirus with CMV promoter-driven expression of GFP; AdCMV-MAFA: Adenovirus with CMV promoter-driven expression of MAFA; AdCMV-hNEUROD1: Adenovirus with CMV promoter-driven expression of NEUROD1; Ad-CMV-PDX1: Adenovirus with CMV promoter-driven expression of PDX1; Ad-RIP-luciferase: Adenovirus with rat insulin promoter-driven expression of luciferase; ALT: Alanine transferase; AST: Aspartate transaminase; GFP: Green fluorescent protein; GLUT2: Glucose transporter 2; IPC

sheet: Insulin-producing cell sheet; IPCs: Insulin-producing cells; MAFA: v-maf musculoaponeurotic fibrosarcoma oncogene family, protein A;

MOI: Multiplicity of infection; NEUROD1: Neuronal differentiation 1; NGN3: Neurogenin-3; NKX2.2: NK2 homeobox 2; NKX6.1: NK6 homeobox 1; PAX4: Paired box 4; PDX1: Pancreatic and duodenal homeobox 1; PIPA Am: Poly(N-isopropylacrylamide); PV: Portal vein; RIP: Rat insulin promotor; STZ: Streptozotocin; TEM: Transmission electron microscopy

\section{Acknowledgements}

Not applicable.

\section{Disclosures}

The authors of the article do not have any commercial association (e.g., consultancies, stock ownership, equity interests, patent-licensing arrangements) that might pose a conflict of interest in connection with the submitted article.

\section{Authors' contributions \\ S.C.K. and I.K.S. conceived the study, designed the experiments, and supervised the project. Y.N.L. and H.J.Y. conducted the experiments and wrote the manuscript. E.H.S., J.O., and S.L. assisted with the animal experiments. T.O. carried out the cell sheet preparation, manipulation, and transplantation. S.F. developed the insulin-producing cell, performed the data quality checks, and reviewed the manuscript. H.J.Y. and I.K.S. illustrated the schematic diagram for isolation, and cell sheet and animal experiments. The authors read and approved the final manuscript.}

\section{Funding}

This study was supported by a grant (No. NRF-2017M3A9C6032060 and NRF2015K1A4A3046807) funded by the Ministry of Education, Science and Technology and a grant (No. 2017-615) from the Asan Institute for Life Sciences, Asan Medical Center, Seoul, Korea. This study was supported by 
Dia-Cure P_37_794, POC-A. 1- A.1.1.4-E-2015 (2016-2021). The funders had no role in study design, data collection, and analysis, the decision to publish, or preparation of the manuscript.

\section{Availability of data and materials}

The data that support the findings of this study are available on request from the corresponding author.

\section{Ethics approval and consent to participate}

This animal study was reviewed and approved by the Institutional Anima Care and Use Committee (IACUC No. 2015-12-133) Asan Institute for Life Sciences. The committee abides by the Institute of Laboratory Animal Resources (ILAR) guide. We obtained written informed consent from all the patients who participated in this study. All experiment protocol of human liver cell isolation was carried out according to the guidelines and with the approval of the Institutional Review Board of Asan Medical Center (IRB number: 20141182 Seoul, Republic of Korea)

\section{Consent for publication}

Not applicable.

\section{Competing interests}

Dr. Teruo Okano is a founder and Director of the Scientific Advisory Board of CellSeed Inc., which has licenses for certain cell sheet-related technologies and patents from Tokyo Women's Medical University. Ms. Yu Na Lee, Ms. Hye-Jin Yi, Ms. Eun Hye Seo, Ms. Jooyun Oh, Dr. Song Lee, Dr. Sarah Ferber, Dr. In Kyong Shim, and Dr. Song Cheol Kim declare no potential conflict of interest. The authors declare that there are no other financial or non-financial competing interests.

\section{Author details}

${ }^{1}$ Asan Institute for Life Sciences, Asan Medical Center, University of Ulsan College of Medicine, Seoul, Republic of Korea. ${ }^{2}$ Sheba Regenerative Medicine, Stem Cells and Tissue Engineering Center, Sheba Medical Center, Tel-Hashomer, Israel. ${ }^{3}$ Institute of Advanced Biomedical Engineering and Science, Tokyo Women's Medical University, Tokyo, Japan. ${ }^{4}$ Cell Sheet Tissue Engineering Center, Department of Pharmaceutics and Pharmaceutical Chemistry, University of Utah, Salt Lake City, USA. ${ }^{5}$ Department of Surgery, Asan Medical Center, University of Ulsan College of Medicine, Seoul, Republic of Korea.

Received: 19 March 2020 Accepted: 7 December 2020 Published online: 06 January 2021

\section{References}

1. Dholakia S, Mittal S, Quiroga I, Gilbert J, Sharples EJ, Ploeg RJ, Friend PJ. Pancreas transplantation: past, present, future. Am J Med. 2016;129(7):667-73.

2. Group AtCCRiDS. Effects of intensive glucose lowering in type 2 diabetes. $N$ Engl J Med. 2008;358(24):2545-59.

3. Group TAC. Intensive blood glucose control and vascular outcomes in patients with type 2 diabetes. N Engl J Med. 2008;358(24):2560-72.

4. Duckworth W, Abraira C, Moritz T, Reda D, Emanuele N, Reaven PD, Zieve FJ, Marks J, Davis SN, Hayward R, et al. Glucose control and vascular complications in veterans with type 2 diabetes. N Engl J Med. 2009;360(2): 129-39.

5. Group TDCaCTR. The effect of intensive treatment of diabetes on the development and progression of long-term complications in insulindependent diabetes mellitus. N Engl J Med. 1993:329(14):977-86.

6. Group UPDSU. Intensive blood-glucose control with sulphonylureas or insulin compared with conventional treatment and risk of complications in patients with type 2 diabetes (UKPDS 33). Lancet. 1998;352(9131):837-53.

7. Ryan EA, Paty BW, Senior PA, Bigam D, Alfadhli E, Kneteman NM, Lakey JR, Shapiro AM. Five-year follow-up after clinical islet transplantation. Diabetes. 2005;54(7):2060-9.

8. Lysy PA, Corritore E, Sokal EM. New insights into diabetes cell therapy. Cur Diab Rep. 2016;16(5):38.

9. Meivar-Levy I, Sapir T, Berneman D, Weissbach T, Polak-Charcon S, Ravassard P, Tzakis AG, Mor E, Ricordi C, Ferber S. Human liver cells expressing albumin and mesenchymal characteristics give rise to insulin-producing cells. J Transp Secur. 2011;2011:252387.
10. Zaret KS, Grompe M. Generation and regeneration of cells of the liver and pancreas. Science. 2008;322(5907):1490-4.

11. Sapir T, Shternhall K, Meivar-Levy I, Blumenfeld T, Cohen H, Skutelsky E, Eventov-Friedman S, Barshack I, Goldberg I, Pri-Chen S, et al. Cellreplacement therapy for diabetes: generating functional insulin-producing tissue from adult human liver cells. Proc Natl Acad Sci U S A. 2005;102(22): 7964-9.

12. Zhou Q, Brown J, Kanarek A, Rajagopal J, Melton DA. In vivo reprogramming of adult pancreatic exocrine cells to beta-cells. Nature. 2008;455(7213):627-32

13. Banga A, Greder LV, Dutton JR, Slack JM. Stable insulin-secreting ducts formed by reprogramming of cells in the liver using a three-gene cocktail and a PPAR agonist. Gene Ther. 2014;21(1):19-27.

14. Berneman-Zeitouni D, Molakandov K, Elgart M, Mor E, Fornoni A, Dominguez MR, Kerr-Conte J, Ott M, Meivar-Levy I, Ferber S. The temporal and hierarchical control of transcription factors-induced liver to pancreas transdifferentiation. PLoS One. 2014:9(2):e87812.

15. Matsuura K, Utoh R, Nagase K, Okano T. Cell sheet approach for tissue engineering and regenerative medicine. J Control Release. 2014;190:228-39.

16. Shapiro AM, Pokrywczynska M, Ricordi C. Clinical pancreatic islet transplantation. Nat Rev Endocrinol. 2017:13(5):268-77.

17. Medarova Z, Evgenov NV, Dai G, Bonner-Weir S, Moore A. In vivo multimodal imaging of transplanted pancreatic islets. Nat Protoc. 2006;1(1): 429-35.

18. Bennet W, Sundberg B, Groth CG, Brendel MD, Brandhorst D, Brandhorst $H$, Bretzel RG, Elgue G, Larsson R, Nilsson B, et al. Incompatibility between human blood and isolated islets of Langerhans: a finding with implications for clinical intraportal islet transplantation? Diabetes. 1999;48(10):1907-14.

19. Bennet W, Groth CG, Larsson R, Nilsson B, Korsgren O. Isolated human islets trigger an instant blood mediated inflammatory reaction: implications for intraportal islet transplantation as a treatment for patients with type 1 diabetes. Ups J Med Sci. 2000;105(2):125-33.

20. Lee RH, Kim B, Choi I, Kim H, Choi HS, Suh K, Bae YC, Jung JS. Characterization and expression analysis of mesenchymal stem cells from human bone marrow and adipose tissue. Cell Physiol Biochem. 2004;14(46):311-24.

21. Zhang C, Suckow AT, Chessler SD. Altered pancreatic islet function and morphology in mice lacking the Beta-cell surface protein neuroligin-2. PLoS One. 2013;8(6):e65711.

22. Hirabaru M, Kuroki T, Adachi T, Kitasato A, Ono S, Tanaka T, Matsushima H, Sakai $Y$, Soyama A, Hidaka M, et al. A method for performing islet transplantation using tissue-engineered sheets of islets and mesenchymal stem cells. Tissue Eng Part C Methods. 2015;21(12):1205-15.

23. Choi J, Woo HN, Ju EJ, Jung J, Chung HK, Park J, Park SS, Shin SH, Park HJ, Lee JS, et al. Immunocytes as a biocarrier to delivery therapeutic and imaging contrast agents to tumors. J Nanomater. 2012

24. Guo XR, Wang XL, Li MC, Yuan YH, Chen Y, Zou DD, Bian L, Li DS. PDX-1 mRNA-induced reprogramming of mouse pancreas-derived mesenchymal stem cells into insulin-producing cells in vitro. Clin Exp Med. 2015:15(4):501-9.

25. Raikwar SP, Zavazava N. Insulin producing cells derived from embryonic stem cells: are we there yet? J Cell Physiol. 2009;218(2):256-63.

26. Shahjalal HM, Shiraki N, Sakano D, Kikawa K, Ogaki S, Baba H, Kume K, Kume S. Generation of insulin-producing $\beta$-like cells from human iPS cells in a defined and completely xeno-free culture system. J Mol Cell Biol. 2014;6(5): 394-408.

27. Butler PC, Meier JJ, Butler AE, Bhushan A. The replication of beta cells in normal physiology, in disease and for therapy. Nat Clin Pract Endocrinol Metab. 2007;3(11):758-68.

28. Cavelti-Weder C, Li W, Zumsteg A, Stemann M, Yamada T, Bonner-Weir S, Weir G, Zhou Q. Direct reprogramming for pancreatic beta-cells using key developmental genes. Curr Pathobiol Rep. 2015;3(1):57-65.

29. Shen J, Cheng Y, Han Q, Mu Y, Han W. Generating insulin-producing cells for diabetic therapy: existing strategies and new development. Ageing Res Rev. 2013:12(2):469-78.

30. Zhu Y, Liu Q, Zhou Z, Ikeda Y. PDX1, Neurogenin-3, and MAFA: critical transcription regulators for beta cell development and regeneration. Stem Cell Res Ther. 2017:8(1):240

31. Akinci E, Banga A, Greder LV, Dutton JR, Slack JM. Reprogramming of pancreatic exocrine cells towards a beta (beta) cell character using Pdx1, Ngn3 and MafA. Biochem J. 2012:442(3):539-50. 
32. Ren J, Jin P, Wang E, Liu E, Harlan D, Li X, Stroncek D. Pancreatic islet cell therapy for type I diabetes: understanding the effects of glucose stimulation on islets in order to produce better islets for transplantation, vol. 5; 2007.

33. You YH, Ham DS, Park HS, Rhee M, Kim JW, Yoon KH. Adenoviruses expressing PDX-1, BETA2/NeuroD and MafA induces the transdifferentiation of porcine neonatal pancreas cell clusters and adult pig pancreatic cells into beta-cells. Diabetes Metab J. 2011;35(2):119-29.

34. Zhang C, Moriguchi T, Kajihara M, Esaki R, Harada A, Shimohata H, Oishi $H$, Hamada M, Morito N, Hasegawa K, et al. MafA is a key regulator of glucosestimulated insulin secretion. Mol Cell Biol. 2005;25(12):4969-76.

35. Kataoka K, Han Sl, Shioda S, Hirai M, Nishizawa M, Handa H. MafA is a glucose-regulated and pancreatic beta-cell-specific transcriptional activator for the insulin gene. J Biol Chem. 2002;277(51):49903-10

36. Kataoka K, Shioda S, Ando K, Sakagami K, Handa H, Yasuda K. Differentially expressed Maf family transcription factors, C-Maf and MafA, activate glucagon and insulin gene expression in pancreatic islet alpha- and betacells. J Mol Endocrinol. 2004;32(1):9-20.

37. Matsuoka TA, Artner I, Henderson E, Means A, Sander M, Stein R. The MafA transcription factor appears to be responsible for tissue-specific expression of insulin. Proc Natl Acad Sci U S A. 2004;101(9):2930-3.

38. Roscioni SS, Migliorini A, Gegg M, Lickert H. Impact of islet architecture on beta-cell heterogeneity, plasticity and function. Nat Rev Endocrinol. 2016; 12(12):695-709.

39. Meda P. Protein-mediated interactions of pancreatic islet cells. Scientifica. 2013;2013:621249.

40. Gefen-Halevi S, Rachmut IH, Molakandov K, Berneman D, Mor E, Meivar-Levy I, Ferber S. NKX6.1 promotes PDX-1-induced liver to pancreatic beta-cells reprogramming. Cell Reprogram. 2010;12(6):655-64.

41. Shimizu T, Yamato M, Kikuchi A, Okano T. Cell sheet engineering for myocardial tissue reconstruction. Biomaterials. 2003;24(13):2309-16.

42. Takagi R, Yamato M, Kanai N, Murakami D, Kondo M, Ishii T, Ohki T, Namiki $\mathrm{H}$, Yamamoto M, Okano T. Cell sheet technology for regeneration of esophageal mucosa. World J Gastroenterol. 2012;18(37):5145-50.

43. Shapiro AM, Lakey JR, Ryan EA, Korbutt GS, Toth E, Warnock GL, Kneteman NM, Rajotte RV. Islet transplantation in seven patients with type 1 diabetes mellitus using a glucocorticoid-free immunosuppressive regimen. N Engl J Med. 2000;343(4):230-8.

44. Ryan EA, Lakey JR, Rajotte RV, Korbutt GS, Kin T, Imes S, Rabinovitch A, Elliott JF, Bigam D, Kneteman NM, et al. Clinical outcomes and insulin secretion after islet transplantation with the Edmonton protocol. Diabetes. 2001;50(4): 710-9.

45. Baidal DA, Ricordi C, Berman DM, Alvarez A, Padilla N, Ciancio G, Linetsky E, Pileggi A, Alejandro R. Bioengineering of an intraabdominal endocrine pancreas. N Engl J Med. 2017;376(19):1887-9.

46. Bruni A, Gala-Lopez B, Pepper AR, Abualhassan NS, Shapiro AJ. Islet cell transplantation for the treatment of type 1 diabetes: recent advances and future challenges. Diabetes Metab Syndr Obes. 2014;7:211-23.

47. Stocking KL, Jones JC, Everds NE, Buetow BS, Roudier MP, Miller RE. Use of low-molecular-weight heparin to decrease mortality in mice after intracardiac injection of tumor cells. Comp Med. 2009;59(1):37-45.

\section{Publisher's Note}

Springer Nature remains neutral with regard to jurisdictional claims in published maps and institutional affiliations.

Ready to submit your research? Choose BMC and benefit from:
- fast, convenient online submission
- thorough peer review by experienced researchers in your field
- rapid publication on acceptance
- support for research data, including large and complex data types
- gold Open Access which fosters wider collaboration and increased citations
- maximum visibility for your research: over 100M website views per year
At BMC, research is always in progress.
Learn more biomedcentral.com/submissions

